\title{
PRODUÇÃO PRIMÁRIA LÍQUIDA EM ÁREA QUEIMADA E NÃO QUEIMADA DE CAMPO SUJO DE CERRADO (PLANALTINA - DF)
}

\author{
Maria Lucia Meirelles ${ }^{1}$ \\ Raimundo Paulo Henriques ${ }^{2}$
}

Recebido em 12-06-91. Aceito em 26-08-92.

RESUMO - Foi estimada a produçāo primária líquida aérea de duas áreas de campo sujo de cerrado em Planaltina (DF), sendo uma preservada e outra queimada no início do experimento. A produção foi estimada através das diferenças entre o peso seco da fitomassa herbácea aérea coletada quinzenalmente. O estudo foi realizado de outubro de 1980 a abril de 1981, que corresponde ao período das chuvas no DF. A produção primária líquida aérea do estrato herbáceo da área queimada $\left(176 \pm 33 \mathrm{~g} \mathrm{~m}^{-2}\right)$ foi maior que a observada na área que nāo sofreu queima $\left(108 \pm 26 \mathrm{~g} \mathrm{~m}^{-2}\right)$. A eficiência da conversāo de energia solar para matéria seca foi de $0,19 \pm 0,04 \%$ para a área queimada e $0,12 \pm 0,03 \%$ na área preservada. A produçāo quinzenal apresentou correlação significativa com a precipitação e água no solo, demonstrando ser a água um fator limitante da produtividade do estrato herbáceo em área de campo sujo de cerrado.

Palavras-chave: produçāo primária, fogo, cerrado, campo sujo.

ABSTRACT - The above-ground net primary production was estimated for two areas of campo sujo of cerrado, one unburnt and the other initially burnt. Production was estimated by using diferences in the above-ground biomass which was sampled at quarterly intervals. The study was planned to coincide with the wet season, between october 1980 and april 1981. The above-ground net primary production of the herbaceous layer in the burnt area $\left(176 \pm 33 \mathrm{~g} \mathrm{~m}^{-2}\right)$ was higher than in the unburnt area $\left(108 \pm 26 \mathrm{~g} \mathrm{~m}^{-2}\right)$. The efficiency of the conversion of solar energy into dry matter was $0,12 \pm 0,0,03 \%$ for the unburnt campo sujo and $0,19 \pm 0,04 \%$ for the burnt campo sujo. The quartely production figures had significative correlation with precipitation and soil water, showing that the water is a limiting factor to the herbaceous layer primary production in campo sujo of cerrado.

Key-words: primary production, fire, savanna.

1 - Centro de Pesquisa Agropecuária dos Cerrados - Empresa Brasileira de Pesquisa Agropecuária, C.P. 08223, CEP 73301-970. Planaltina, DF - Brasil.

2 - Universidade de Brasília, Departamento de Engenharia Florestal. Brasília, DF. 


\section{Introdução}

O estudo da produção vegetal (primária) é o primeiro passo para o entendimento das transferências de energia entre os diferentes níveis tróficos de um ecossistema.

Observa-se uma grande variação nos valores de produção primária obtidos em diferentes ecossistemas (Evans, 1972). A precipitação (Sims \& Singh, 1978), a evapotranspiração potencial (Lieth, 1961), a evapotranspiração real (Rosenzweig, 1968) e a temperatura atmosférica (Pitt \& Heady, 1978; Graumlich \& Brubaker, 1989) são consideradas como os principais fatores do ambiente responsáveis por estas variações. A variação na produção primária pode ocorrer também devido a outros fatores, como níveis de fertilidade do solo, periodicidade das chuvas, situações de seca nas diferentes fenofases do crescimento, etc. (Shankaranarayan et al., 1985). Além disso, a interação entre os fatores ambientais também deve ser considerada (Sala et al., 1988).

O fogo é um fator ecológico com grande influência na produção primária dos ecossistemas onde ele ocorre. Tem um papel essencial no ciclo sazonal, selecionando estratégias adaptativas de certas plantas e, em alguns casos, mantendo a savana nas zonas onde o clímax verdadeiro é a floresta (Lamotte, 1985). Em várias partes do mundo tem se desenvolvido um manejo de fogo, pois percebe-se que quando o fogo ocorre acidentalmente, as conseqüências para o ecossistema são bem mais trágicas (Coutinho, 1990). Estes incêndios programados previnem o fechamento do dossel arbustivo e arbóreo em pastagens nativas (Hobbs \& Giminghan, 1987). Riggan et al. (1988) também observaram que o fogo severo limita a acumulação de nutrientes e, conseqüentemente, a produtividade.

O fogo ocorre em grande escala no cerrado, sendo largamente utilizado pela população no manejo de pastagens nativas (Filgueiras, 1981). Certas ações do fogo sobre a vegetação do cerrado já foram detectadas. Coutinho (1980) considerou o fogo como um fator ecológico que eleva a temperatura local, acelera a ciclagem dos nutrientes minerais, causa modificações fisionômicas e estruturais da vegetação, estimula a floração e brotamento de algumas espécies nativas e aumenta a produção primária do estrato herbáceo. Alguns estudos sobre a produção em áreas que sofreram a ação do fogo já foram realizados no cerrado (Cavalcanti, 1978; Coutinho et al., 1982; Cesar, 1980; Batmanian, 1983).

O efeito do fogo sobre a produção primária e sua relação com outros fatores ambientais é uma informação básica para o futuro manejo do fogo no cerrado. $O$ presente estudo teve como objetivo comparar a produção primária líquida aérea de duas áreas de campo sujo de cerrado no Distrito Federal, uma que não sofria queima há pelo menos três anos e outra que foi queimada na início do experimento. Procurou-se, também, detectar as correlações significativas entre certos fatores ambientais e a produção primária líquida em cada uma das áreas. 


\section{Material e Métodos}

A área de estudo está situada no Centro de Pesquisa Agropecuária dos Cerrados, CPAC-EMBRAPA, na cidade de Planaltina, DF, nas coordenadas $15^{\circ} 36^{\prime} 36^{\prime \prime} \mathrm{S}$ e $47^{\circ} 44^{\prime} 21^{\prime \prime}$ W. A vegetação da área foi considerada como campo sujo de cerrado por apresentar apenas poucos arbustos, sem árvores e um estrato herbáceo contínuo (Ribeiro et al. 1982). A área localiza-se em um Latossolo Vermelho-Amarelo com textura areia franca no horizonte $\mathrm{A}$, franco-arenosa no horizonte $\mathrm{B}_{1}$, e franco-argiloarenosa nos horizontes $\mathrm{B}_{21}$ e $11 \mathrm{~B}_{22} \mathrm{cn}$ (com concreções).

As duas parcelas estudadas foram:

a) Não queimada $(40 \mathrm{~m} \mathrm{X} 50 \mathrm{~m})$ - encontrava-se no início do experimento protegida contra o fogo e qualquer ação externa há pelo menos três anos.

b) Queimada (40m X 50m ) - vizinho à testemunha e sofreu ação do fogo em 03/10/ 1980.

As duas parcelas eram contíguas, não sendo visualizada nenhuma diferença em relação à estrutura vegetacional e declividade na área total amostrada $(80 \mathrm{~m} \mathrm{X} \mathrm{50m).}$

As coletas de dados foram realizadas no período de 09/10/1980 a 23/04/1981, que corresponde ao período das chuvas. É usual, na obtenção da produção primária de uma área, levar-se em consideração, apenas o período de crescimento da vegetação. Coutinho et al (1982) demonstraram que, nos meses de maio a setembro (período da seca), ocorre uma paralisação da produção primária e salientaram que o período de crescimento da vegetação herbácea do cerrado ocorre na época de chuvas.

Quinzenalmente a fitomassa do estrato herbáceo de cada parcela foi amostrada aleatoriamente através de dez quadrados de $1 \mathrm{~m}^{2}$. Coletava-se, com o auxílio de uma tesoura de poda, todo o material herbáceo aéreo. Posteriormente, a fitomassa viva (folhas verdes) era separada manualmente da fitomassa morta (folhas amareladas), sendo a fitomassa viva seca em estufa a $80^{\circ} \mathrm{C}$, por 48 horas e a fitomassa morta seca ao ar (Lieth, 1968a). A separação e a secagem do material foram realizadas no Laboratório de Ecologia da Universidade de Brasília. Depois da pesagem do material, foram calculadas as médias dos valores obtidos para as fitomassas viva e morta, nos dez quadrados, em cada uma das coletas. Com os dados obtidos foram feitas regressões polinominais para a obtenção das curvas que representassem o incremento ou redução de fitomassa viva e morta, para a área queimada e não queimada, no período de estudo.

A produção primária líquida aérea (PPLA) foi calculada através do método de análise dos picos de fitomassa viva (Singh et al., 1975). Foram calculados os incrementos de fitomassa viva para cada quinzena, através da subtração do valor de fitomassa viva obtida no final da quinzena pelo valor inicial. Para o cálculo final de PPLA foi realizado o somatório de todos os valores positivos obtidos. Foi retirada do cálculo da PPLA a fitomassa viva que estava presente na área no início do experimento e que não foi produzida no período de crescimento estudado. Isso 
se deu no momento em que se calculou o incremento obtido na primeira quinzena. Foram coletados diariamente dados de temperatura média do ar, precipitação e radiação solar total numa estação meteorológica que distava $640 \mathrm{~m}$ da área de estudo. A partir dos dados obtidos nesta estação foi calculada a evapotranspiração potencial, segundo o método de Penman (1948). Foram também obtidos dados da porcentagem de água no solo, por gravimetria, em amostras retiradas de $15 \mathrm{em} 15$ $\mathrm{cm}$ até $90 \mathrm{~cm}$ de profundidade. As amostras foram coletadas, semanalmente, em dois pontos aleatórios de cada parcela. Foram feitas correlações simples entre os dados obtidos das variáveis ambientais acima descritas e os dados da PPLA obtidos quinzenalmente. Os dados de radiação solar foram também utilizados para o cálculo de eficiência da vegetação na produção de matéria seca (eficiência ecológica), que corresponde à razão entre a energia produzida pela fotossíntese e o total de radiação solar fotossinteticamente ativa recebido durante um certo período de tempo (Lieth, 1968b). A radiação fotossinteticamente ativa foi considerada como sendo $50 \%$ do total da radiação solar (Monteith, 1973).

\section{Resultados e discussão}

Fatores ambientais

Na Tabela 1 têm-se os resultados das análises físico-químicas do solo. O solo é ácido e de baixa fertilidade, fatores que podem limitar a produtividade primária na área.

Tabela 1 - Análises físicas e químicas de um perfil de solo localizado entre as parcelas queimada e não queimada em um campo sujo de cerrado (CPAC, Planaltina-DF).

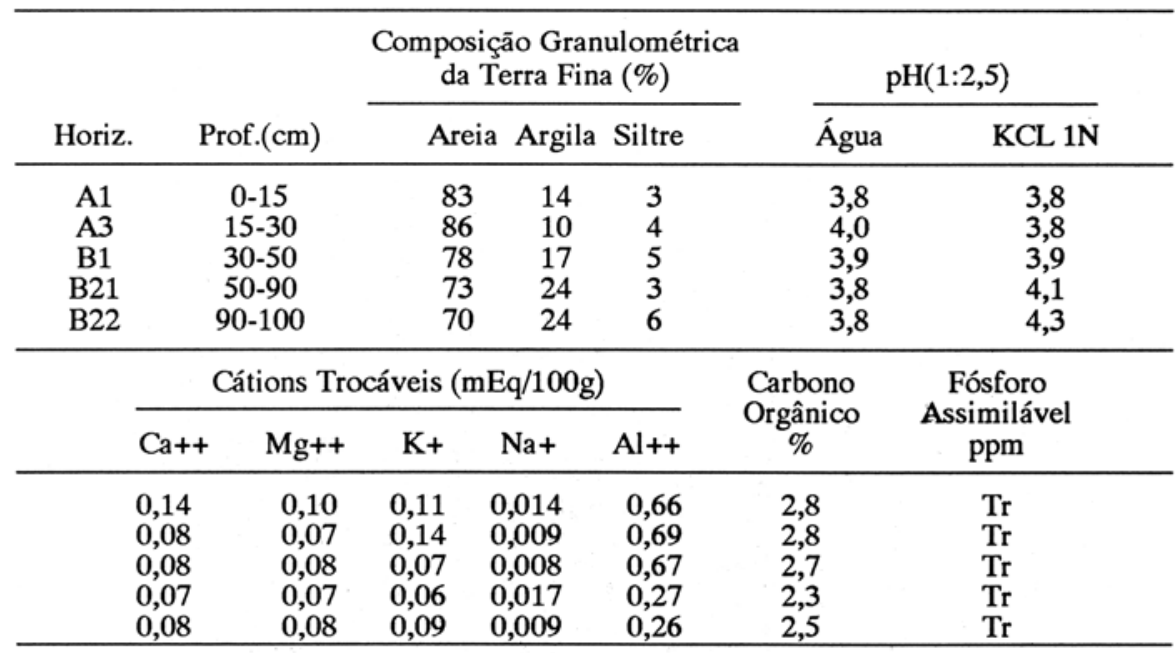


Na Figura 1 têm-se os valores de precipitação total e de temperatura média mensal do período de estudo, comparados com os dados médios de 30 anos, obtidos na estação meteorológica de Formosa (GO). Em relação à precipitação, a maior diferença entre o ano de estudo e a média de 30 anos foi o mês de fevereiro, quando o valor obtido foi menor que o médio, fato que se inverte em março. Isto deveu-se à ocorrência do veranico (período de estiagem que ocorre freqüentemente durante a estação chuvosa) entre a segunda quinzena de fevereiro e a primeira quinzena de março daquele ano. A temperatura média do ar foi um pouco menor na área de estudo, provavelmente por se encontrar numa altitude maior $(1175 \mathrm{~m})$ do que a estação metereológica de Formosa (912 m).

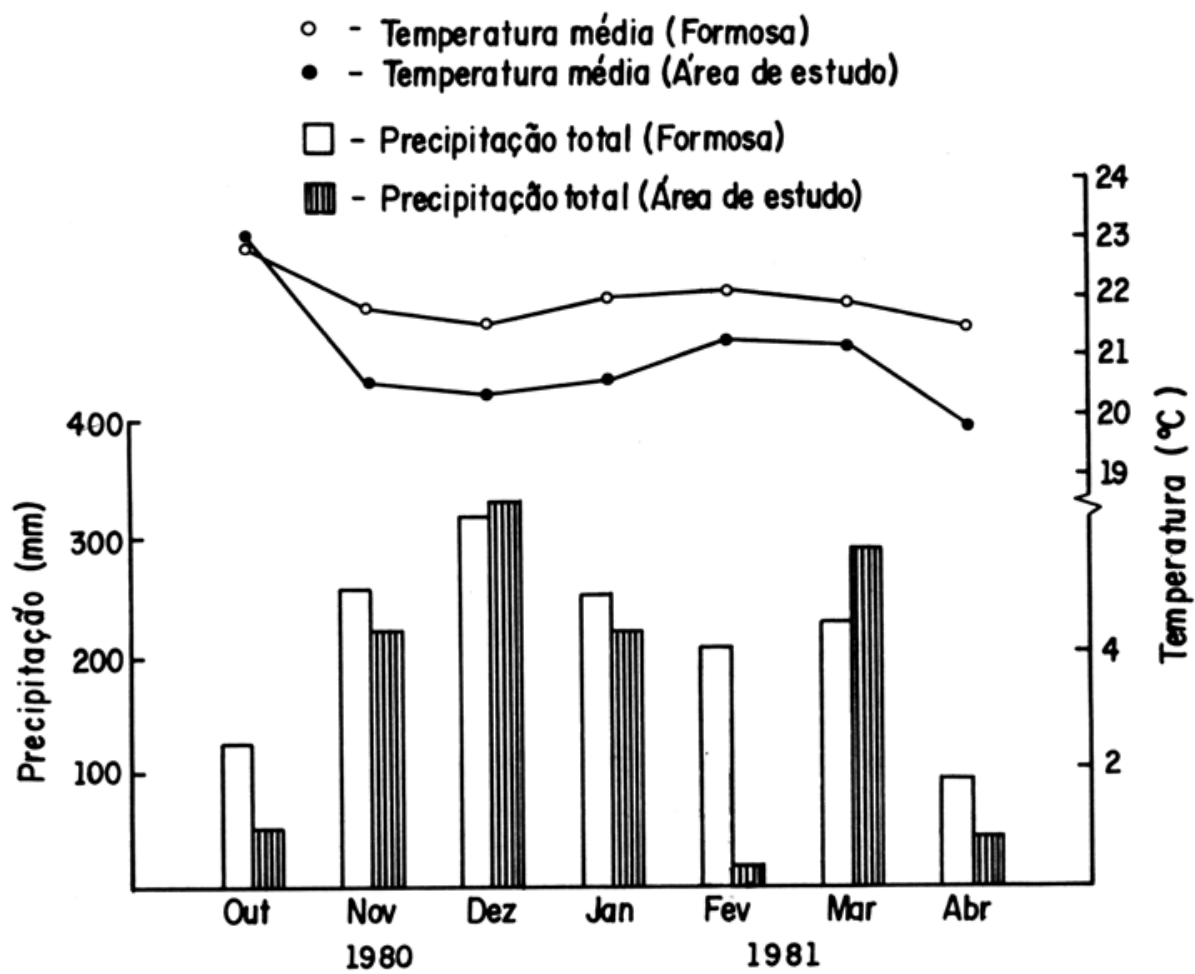

Figura 1 - Precipitação total mensal e temperatura média mensal de maio de 1980 a abril de 1981 obtidas em uma estação meterológica que distava $640 \mathrm{~m}$ da área de estudo (CPAC, Planaltina-DF). Têm-se também, para os mesmos parâmetros, os valores médios de 1930 a 1960 obtidos na estação meteorológica de Formosa (GO). 
Fitomassa e produção primária

Os valores de fitomassa viva e morta na parcela não queimada encontram-se na Figura 2a. Observa-se, no decorrer do estudo, um aumento gradual na quantidade de fitomassa viva e uma diminuição na quantidade de fitomassa morta. O maior valor de fitomassa viva $\left(97,4 \pm 7,6 \mathrm{~g} \mathrm{~m}^{-2}\right)$ foi obtido no dia 15/04/81 e o de fitomassa morta $\left(473,1 \pm 54,9 \mathrm{~g} \mathrm{~m}^{-2}\right)$ no dia $04 / 12 / 80$, quando também ocorreu o menor valor de fitomassa viva $\left(51,6 \pm 5,2 \mathrm{~g} \mathrm{~m}^{-2}\right)$. O menor valor de fitomassa morta $\left(179,8 \pm 14,2 \mathrm{~g} \mathrm{~m}^{-2}\right)$ foi obtido no dia $02 / 04 / 81$. A razão entre os valores de fitomassa morta e viva foi, aproximadamente, $6: 1$ no final da época seca (09/10/ $80)$ e $2: 1$ no final da época chuvosa $(02 / 04 / 81)$. Os dados de fitomassa morta apresentaram uma grande variação em cada amostragem, sugerindo uma distribuição não homogênea de matéria morta na área. Apesar desta variabilidade, é perceptível a diminuição de quantidade de matéria morta no decorrer do período da chuva, demonstrando o aumento da atividade decompositora.

Os valores de fitomassa viva e morta na parcela queimada encontram-se na Figura $2 \mathrm{~b}$. Ocorreu um aumento gradual e significativo na quantidade de fitomassa viva que, a partir de janeiro, atingiu valores maiores do que os observados na parcela não queimada. A partir de março ocorreu um declínio na quantidade de fitomassa viva que coincidiu com o início da estação seca. Os valores de fitomassa morta foram sempre inferiores ao de fitomassa viva, mas apresentaram o mesmo padrão de variação estacional. O maior valor de fitomassa viva foi $158,1 \pm 9,64 \mathrm{~g}$ $\mathrm{m}^{-2}$, obtido em 26/03/81 quando ocorreu o maior valor de fitomassa morta $(65,84 \pm$ $\left.6,6 \mathrm{gm}^{-2}\right) \mathrm{em}$ um período que corresponde ao final da época chuvosa. $\mathrm{O}$ maior valor da razão entre fitomassa morta e viva foi 1:2 obtido em 26/03/81.

A produção primária líquida aérea (PPLA) para o período de crescimento, foi de $108 \pm 26 \mathrm{~g} \mathrm{~m}^{-2}$ para a parcela não queimada e de $176 \pm 33 \mathrm{~g} \mathrm{~m}^{-2}$ na parcela queimada.

Relação entre a produção primária e fatores ambientais

Na tabela 2 são mostrados os coeficientes de correlação simples entre a produção primária e fitomassa morta e os fatores do ambiente. Os valores correspondem ao somatório dos dados obtidos em cada quinzena. Na parcela não queimada obtiveram-se correlações significativas da produção primária com a precipitação $(\mathrm{r}=0,47,0,025<\mathrm{p}<0,05 ; \mathrm{N}=14)$.e com a porcentagem de água no solo na profundidade de $6 \varnothing$ a $9 \varnothing \mathrm{cm}(\mathrm{r}=0,51 ; 0,025<\mathrm{p} \leq 0,05 ; \mathrm{N}=14)$. Na parcela queimada obteve-se uma correlação positiva entre a produção primária e a precipitação $(r=0,66 ; 0,005<p \leq 0,025 ; N=13)$. Foram testadas também correlações entre os valores de produção primária de uma determinada quinzena e os valores de fatores ambientais, obtidos na quinzena anterior. Não foi observada nenhuma correlação. 

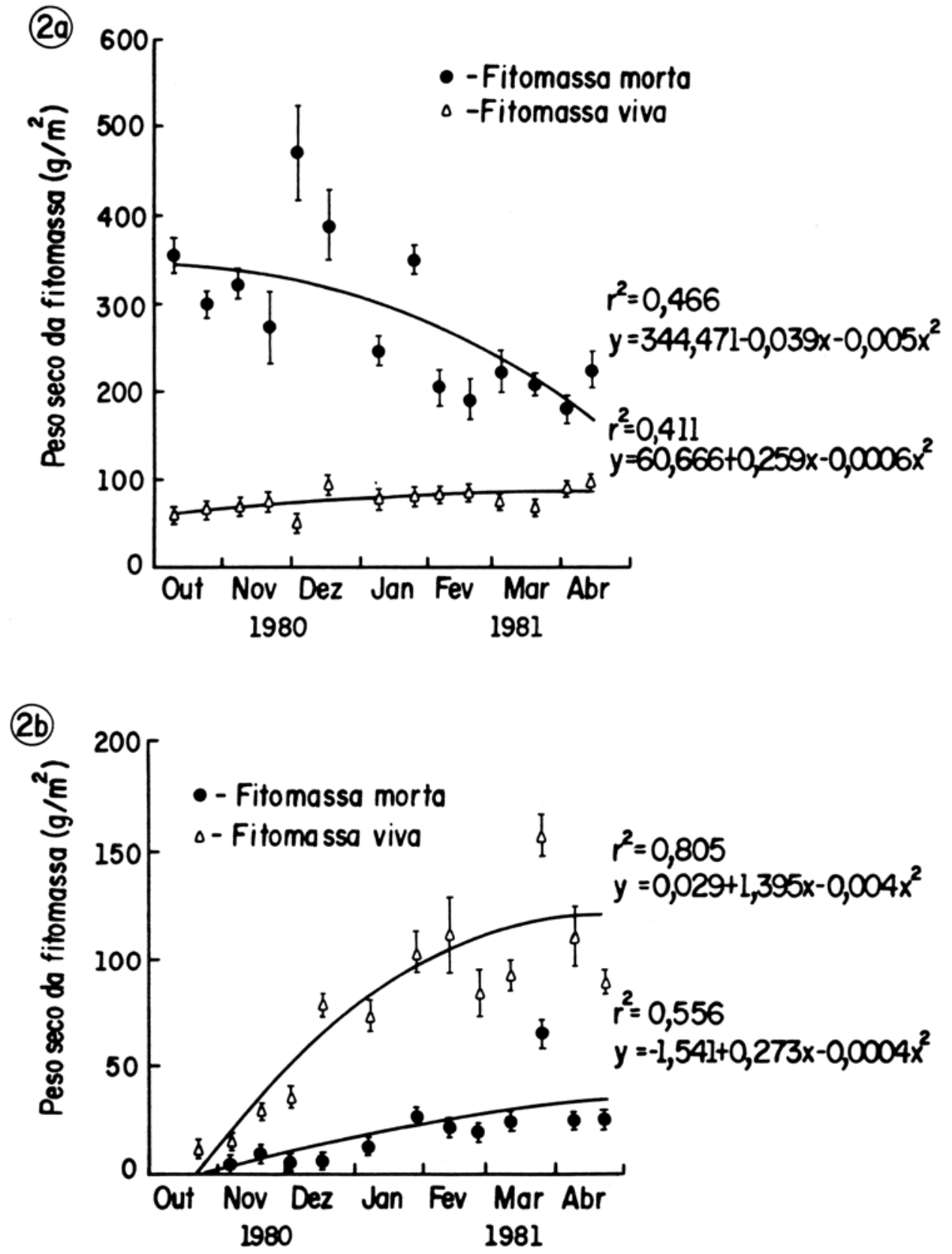

Figura 2 - Variação da fitomassa aérea viva e morta de um campo sujo de cerrado em Planaltina, DF: (2a) parcela não queimada, (2b) parcela queimada no inicio do experimento. Valores médios, com os erros padrões e as curvas obtidas por regressão polinomial. 
Tabela 2 - Coeficientes de correlação simples entre a produção primária líquida aérea e a fitomassa morta e diversos fatores ambientais para as parcelas não queimada e queimada de uma área de campo sujo de cerrado (CPAC, Planaltina-DF).

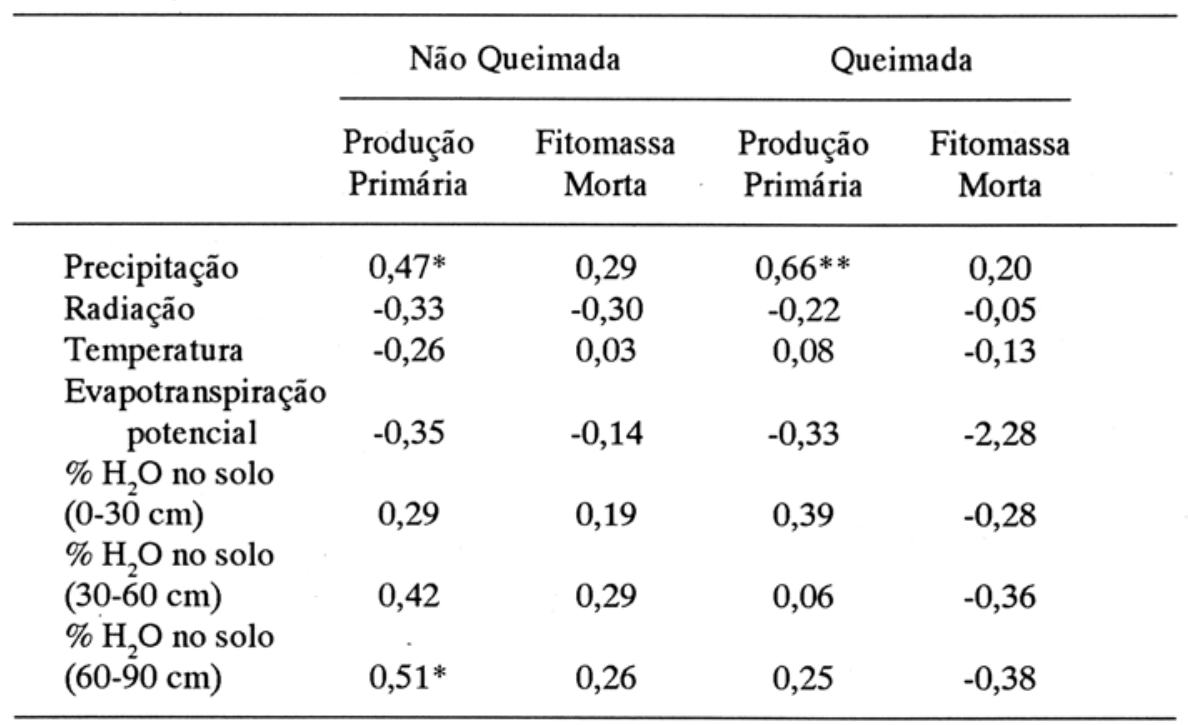

$* 0,025<\mathrm{p}<0,05$

${ }^{* *} 0,005<\mathrm{p}<0,025$

A eficiência ecológica (fotossintética) da vegetação na parcela não queimada foi de $0,12 \pm 0,03 \%$ e na parcela queimada $0,19 \pm 0,04 \%$.

Um ecossistema, para ser bem conservado e manejado, necessita ser entendido. Várias informações básicas são necessárias, como, por exemplo, a quantidade de fitomassa viva e morta, que é um reflexo da produção primária e da velocidade decompositora do ecossistema. Neste estudo a quantidade de fitossama viva no início da época das chuvas é menor que a no final da estação chuvosa, indicando que não ocorre uma produção primária líquida na época da seca e que a época das chuvas é o período de crescimento da vegetação herbácea.

Os dados aqui obtidos de produção primária líquida aérea (PPLA) para o período de crescimento foram relativamente baixos se comparados com a PPLA de outras savanas do mundo (Bourlière \& Hadley, 1970). A PPLA é maior na vegetação herbácea das savanas de Shika na Nigéria $\left(680 \mathrm{~g} \mathrm{~m}^{-2}\right)$ e nos llanos da Venezuela (240-404 $\left.\mathrm{g} \mathrm{m}^{-2}\right)$. Na vegetação herbácea da área de savana do Senegal $\left(40 \mathrm{~g} \mathrm{~m}^{-2}\right)$ e África do Sul $\left(75-110 \mathrm{~g} \mathrm{~m}^{-2}\right)$ a PPLA é menor. Nas duas últimas localidades a quantidade de chuva anual é menor que a observada na região dos Cerrados. 
Comparando-se a PPLA obtida na parcela não queimada (108 $\left.\pm 26 \mathrm{~g} \mathrm{~m}^{-2}\right)$ com a obtida na parcela queimada $\left(176 \pm 33 \mathrm{~g} \mathrm{~m}^{-2}\right)$, observa-se que o fogo estimulou a produção primária no primeiro ano. Este aumento de produtividade devido à ação do fogo já tinha sido observado em savanas da região tropical, nos llanos venezuelanos (San Jose \& Medina, 1975) e também na região temperada, como por exemplo nas pradarias americanas (Kucera \& Ehrenreich, 1962).

Cesar (1980) obteve uma PPLA de $370 \mathrm{~g} \mathrm{~m}^{-2}$ em campo sujo de cerrado queimado, um valor maior que o aqui obtido. Isso provavelmente se deveu ao solo (Tabela 1) apresentar $\mathrm{pH}$, concentração de $\mathrm{Ca}++, \mathrm{Mg}++, \mathrm{K}+$ e fósforo assimilável menores, a lém de uma maior concentração de $\mathrm{Al}+++$, se comparado com o solo da área de estudo de Cesar (1980). Batmanian (1983), em estrato rasteiro de cerrado "sensu strictu", observou uma PPLA maior na área não queimada $\left(327 \mathrm{~g} \mathrm{~m}^{-2}\right)$ do que na área queimada $\left(242 \mathrm{~g} \mathrm{~m}^{-2}\right)$. Este resultado foi contrário ao aqui obtido. Isto ocorreu devido à utilização de métodos diferentes para o cálculo da PPLA nos dois estudos. Para Batmanian (1983), a PPLA foi considerada como o valor máximo de fitomassa encontrada durante todo o período de estudo, não sendo separada a fitomassa viva da morta. Devido ao grande acúmulo de fitomassa seca de outros anos, este método superestima a PPLA, quando utilizado em áreas não queimadas de cerrado.

Comparando-se a eficiência ecológica da parcela não queimada $(0,12 \pm$ $0,03 \%$ ) com a obtida em outras partes do mundo (Jordan, 1971), em vários locais ela é maior, como em uma savana de Minnesota $(0,73 \%)$, nas pradarias altas do Missouri $(0,51 \%)$ e em ervas perenes do Japão $(0,41 \%)$. Já em um deserto de "scrub" no Arizona, ela é bem menor $(0,008 \%)$. Golley (1965) obteve em campos perenes na Georgia um valor de eficiência ecológica $(0,15 \%)$ semelhante ao aqui obtido. Apesar de o referido campo encontrar-se em região temperada, tem semelhança com o campo sujo deste estudo por apresentar uma quantidade de fitomassa morta bem maior que a viva. Golley (1965) sugeriu que uma grande quantidade de matéria morta diminui a penetração da radiação solar nas camadas de vegetação mais baixas, diminuindo a sua produtividade. San Jose \& Medina (1975) citaram como possíveis razões para a baixa produtividade dos campos dos llanos venezuelanos a concentração de maior parte da chuva em um período do ano e as condições edáficas desfavoráveis. Os pontos citados acima ocorrem também na região dos Cerrados, correspondendo a uma outra possível justificativa para sua baixa eficiência ecológica. Meirelles (1990) obteve para uma pastagem de Brachiaria decumbens uma eficiência ecológica bem maior $(0,40 \pm 0,09 \%)$ do que a obtida na parcela não queimada $(0,12 \pm 0,03 \%)$. As duas áreas eram próximas e os estudos foram realizados no mesmo período, sendo que a pastagem de Brachiaria decumbens encontrava-se em Latossolo Vermelho-Escuro, um solo com melhores condições do que o solo do campo sujo estudado (Latossolo Vermelho-Amarelo). O solo, como também outros fatores (arquitetura do dossel da vegetação, rotas metabólicas das plantas, etc.), podem ser responsáveis pela diferença de eficiência ecológica observada. 
Existe uma certa carência de dados que sirvam de subsídio na determinação dos fatores ambientais limitantes da produção primária do estrato herbáceo do cerrado. José (1990) observou que o estrato herbáceo de um cerrado "sensu stricto" não apresentava um aumento de PPLA em área que sofreu calagem, mas apresentava um aumento significativo de PPLA na área que sofreu irrigação. Analisandose as correlações obtidas entre as PPLAs e vários fatores do ambiente (Tabela 2), observou-se que as maiores correlações ocorreram com a precipitação e a quantidade de água no solo. Levando-se em consideração que os dados correlacionados foram obtidos na mesma quinzena, conclui-se que a precipitação provoca uma resposta imediata na PPLA. Além disso, observou-se que pequenas variações na precipitação acarretam variações da PPLA, já que os dados foram coletados apenas na época das chuvas. Estes resultados fortalecem a idéia de que a quantidade de água no sistema é um dos fatores ambientais que mais influenciam na produção primária do estrato herbáceo da região dos Cerrados, atuando como fator limitante de sua produtividade.

\section{Referências Bibliográficas}

BATMANIAN, G. J. 1983. Efeitos do fogo sobre a produção primária e a acumulação de nutrientes do estrato rasteiro de um Cerrado. Dissertação de mestrado, Brasília, Distrito Federal. Instituto de Ciências Biológicas, Universidade de Brasília. $77 \mathrm{p}$.

BOURLIERE, F. \& M. HADLEY, 1970. The ecology of Tropical savannas. Annu. Rev. Ecol. Syst. 1: 125-152.

CAVALCANTI, L. M. 1978. Efeito das cinzas resultantes da queimada sobre a produtividade do estrato herbáceo-subarbustivo do Cerrado de Emas. Tese de doutorado, São Paulo. Instituto de Biociências, Universidade de São Paulo, 219 p.

CEZAR, H. L. 1980. Efeitos da queima e corte sobre a vegetação de Campo sujo na Fazenda Água Limpa, Distrito Federal. Dissertação de Mestrado, Brasília, Distrito Federal. Instituto de Ciências Biológicas, Universidade de Brasília. $59 \mathrm{p}$.

COUTINHO, L. M. 1980. As queimadas e seu papel ecológico. Brasil Florestal 44:7-23.

COUTINHO, L. M. 1990. O cerrado - a ecologia do fogo/ Ciência Hoje 12 (68):23-30.

COUTINHO, L. M, Y. S. VUONO \& L.S. LOUSA. 1982. Aspectos ecológicos do fogo no Cerraod. IV. A época da queima e a produtividade primária líquida epigéia do estrato herbáceo-subarbustivo. Revista Brasileira de Botânica 5:37-41.

EVANS, G. C. 1972. The quantitative analysis of plant growth. Blackweoo Scientific Publications, Oxford. Studies in ecology, IV.

FILGUEIRAS, T. S. 1981. O fogo como agente ecológico. Brasil Florestal 46:17-20. GOLLEY, F. B. 1965. Structure and function of an old-field broomsedge community. 
Ecological monographs 35 (1): 113-137.

GRAUMLICH, L. J. \& L. B. BRUBAKER. 1989. Long-term trends in forest net primary productivity: Cascade Mountains, Washington. Ecology 70(2) 405-410.

HOBBS, R. J. \& C. H. GIMINGHAN. 1987.Vegetation: fire and herbivore interactions in heathland. Advances in Ecological Research 16: 87-173.

JORDAN, C. F. 1971. Productivity of a tropical forest and its relation to world pattern of energy storage. Journal of Ecology 59: 127-143.

JOSÉ D. V. 1990. Resposta do estrato rasteiro de um Cerrado à irrigação e a calagem. Dissertação de mestrado, Brasília, Distrito Federal. Instituto de Ciência Biológicas, Universidade de Brasília. 80p.

KUCERA. C. L. \& J. H. EHRENRECICH, 1962. Some effects o annual burning on Central Missouri prairie. Ecology 43(2): 334-336.

LAMOTTE, M. 1985. Some aspects of studies on savanna ecosystems. Tropical Ecology 26(2):89-98.

LIETH, H. 1961. La producción de substancia organica por la capa vegetal terrestre y sus problemas. Acta Cient. Venez, 12:107-114.

LIETH, H. 1968a. The determination of plant dry - matter production with special emphasis on the urderground parts. In: Functioning of terrestrial ecosystems at the primary production level. UNESCO, Paris. P.179-186.

LIETH, H. 1968b. The measurement of calorific values of biological material and the determination of ecological efficiency. In : Functioning of terrestrial ecosystems at the primary production level. UNESCO, Paris. P. 233-242.

MEIRELLES, M. L. 1990. Produção primária de pastagem de Brachiaria decumbens. Revista Ceres 37(209): 16-24.

MONTEITH J. L. 1973. Principles of Environmental Physics, E. Arnold, London, 241p.

PENMAN, H. L. 1948. Natural evaporation from open water bare soil and grass. Roy. Soc. A. 193: 120-145.

PITT, M. D. \& H. F. HEADY 1978. Responses of annual vegetation to temperature and rainfall patterns in Northern California. Ecology 59(2): 336-350.

RIBEIRO, J. F., S. M. SANO \& J.A. SILVA, 1982. Chave preliminar de identificação dos tipos fisionômicos da vegetação dos Cerrados. In: Anais do XXXII Congresso Nacional de Botâmica. Teresina, PI, p. 124-133.

RIGGAN, P. J., S. GODE, P. M. JACKS \& R. N. LOCKWOOK. 1988. Interaction of fire and community development in chaparral of Southern Califórnia. Ecological Monographs 58(3): 155-176.

ROSENZWEIG, M. L. 1968. Net primary produtivity of terrestrial communities: prediction from climatological data. The American Naturalist 102(923): 67-74.

SALA, O. E., W, J. PARTON, L. A. JOYCE \& K.LAUENROTH. 1988. Primary prod'uction of the Central Grassland Region of the United States. Ecology 69(1): 40-45.

SAN JOSE, J. J. \& E. MEDINA, 1975. Effect of fire on organic matter production and water balance in a tropical savanna. In F. B. Golley \& E. Medina. Tropical Ecological Systems-Trends in Terrestrial and Aquatic Reserch. 
Springer Verlag, New York.

SHANKARANARAYAN, K. A., G. G. S. RAO \& B. V. R. RAO. 1985. Grassland productivity and its associative climatic characteristics in Western Rajasthan. Tropical Ecology 26(2): 157-163.

SIMS, P. L. \& J. S. SINGH. 1978. The struture and function of ten Western North American Grasslands. III-Net primary production, turnover and efficiencies of energy captures and water use. Journal of Ecology 66: 573-597.

SINGH, J. S., W. K. LAURENROTH \& A. J. K. STEINHORST. 1975. Review and assessment of various techniques for estimation of net aerial primary production in grasslands from harvest data. The Botanical Review 41(2): 181232. 